\title{
Intermacromolecular Complexation due to Specific Interactions X. The Complexation of Modified Polystyrene [PS(OH)] and Polycaprolactone in Solutions
}

\author{
Hui Zhou, Ming Jiang, ${ }^{\dagger}$ Mei LI, ${ }^{*}$ and Chi $\mathrm{Wu}^{*}$ \\ Institute of Macromolecular Science and Laboratory of Molecular Engineering of Polymers, \\ Fudan University, Shanghai 200433, People's Republic of China \\ * Department of Chemistry, The Chinese University of Hong Kong, Shatin. \\ Hong Kong, People's Republic of China \\ (Received July 1, 1998)
}

\begin{abstract}
Complexation between hydroxyl containing polystyrene (PS), i.e., PS(OH) and polycaprolactone (PCL) by hydrogen bonding in solutions was studied by viscometry and laser light scattering. Formation of the complex strongly depended on hydroxyl content in $\mathrm{PS}(\mathrm{OH})$ in solution. In toluene, polymer coils existed independently when hydroxyl content in PS(OH) was less than $5 \mathrm{~mol} \%$ while components formed complexes when hydroxyl content reached 8 mol\%. No complexation was found in tetrahydrofuran (THF) even when hydroxyl content went up to $20 \mathrm{~mol} \%$. A combination of dynamic and static light scattering showed that in toluene solution, $\mathrm{PS}(\mathrm{OH})$ with $26 \mathrm{~mol} \%$ of hydroxyl formed complex aggregates with higher mass and density but smaller hydrodynamic volume than $\mathrm{PS}(\mathrm{OH})$ containing $8 \mathrm{~mol} \%$ of hydroxyl did.
\end{abstract}

KEY WORDS Complexation/ Modified Polystyrene / Polycaprolactone / Specific Interactions /

In our long-term research on miscibility and complexation of polymer blends due to intermolecular hydrogen bonding, by progressively increasing hydroxyl groups introduced into a component polymer of an otherwise immiscible blend, not only miscibility but also interpolymer complexation has been found possible in bulk. ${ }^{1-6}$ Among proton-donating polymers used in this laboratory, modified polymer $\operatorname{PS}(\mathrm{OH})$, produced by copolymerization of styrene and $p-(2,2,2-$ trifluoro-1-hydroxy-1-trifluoromethyl)ethyl $\alpha$-methylstyrene (HFMS) has drawn much attention. Using nonradiative energy transfer (NRET) spectrofluorimetry for polystyrene $[\mathrm{PS}(\mathrm{OH})] /$ poly(methyl methacrylate) (PMMA) blend, ${ }^{1}$ in which two components were labeled with a fluorescent energy donor and energy acceptor respectively, when the hydroxyl content in $\mathrm{PS}(\mathrm{OH})$ reached $\sim 7-10 \mathrm{~mol} \%$, the blends showed unusually high energy-transfer efficiency, which was double that of the corresponding miscible blends. This indicates that the polymer chains tend to form complexes, in which unlike segments are paired. ${ }^{7}$ This complexation in solution was also found and confirmed by viscometry, ${ }^{2,3}$ NRET ${ }^{2-5}$ and NMR NOE. ${ }^{6}$ For blend PS(OH)/ PMMA in toluene solutions, when the hydroxyl content in $\mathrm{PS}(\mathrm{OH})$ chain is less than about $5 \mathrm{~mol} \%$, unlike macromolecules exist in single chains, and when the hydroxyl content is $8 \mathrm{~mol} \%$ or more, unlike chains coils aggregate. It is remarkable that this transition from the separated coils to complex aggregates in solution corresponds to the transition from ordinary miscibility to complexation in bulk.

By extending research to a variety of polymer pairs composed of proton-donating and proton-accepting polymers, it was concluded that transition from immiscibility to miscibility and then to complexation by increasing hydrogen bonding is a general phenomenon in blends with controllable specific interactions. The

\footnotetext{
${ }^{\dagger}$ To whom correspondence should be addressed.
}

systems studied included poly[styrene-co-( $p$-vinylphenol)] (STVPh)/poly(ethyl methacrylate) (PEMA), ${ }^{8,9}$ $\mathrm{STVPh} /$ poly(styrene-co-vinylpyridine) (STVPy), ${ }^{3,4}$ $\mathrm{PS}(\mathrm{OH}) /$ poly $\left(n\right.$-butyl methacrylate) (PBMA) ${ }^{5}$ poly$\{$ styrene-co-[p-(2-hydropropan-2-yl)styrene $]\}[\mathrm{PS}(t-\mathrm{OH})] /$ poly $(n$-butyl-methacrylate-co-4-vinylpyridine) [P(BMAco-VPy) $],{ }^{10}$ and poly(styrene-co-vinyl benzoic acid) (CPS)/[P(BMA-co-VPy) $]^{11}$ etc.

In all blends mentioned above, both components are amorphous polymers. We studied blends composing both amorphous and crystalline components. ${ }^{12}$ For blends of $\mathrm{PS}(\mathrm{OH})$ and polycaprolactone (PCL), the crystallization of PCL is depressed by mixing with $\mathrm{PS}(\mathrm{OH})$. Particularly, $\mathrm{PS}(\mathrm{OH})$ with relatively large hydroxyl content ( $>8 \mathrm{~mol} \%$ ) may retard the PCL crystallization completely. This is quite different from ordinary miscible blends containing a crystallizable component reported in the literature. ${ }^{13,14}$ This strong depression of crystallization of PCL has been attributed to segment pairing between PCL and PS $(\mathrm{OH})$. This paper studies the complexation of $\mathrm{PS}(\mathrm{OH})$ and PCL in solution with emphasis on the dependence of the complexation on hydroxyl content in $\mathrm{PS}(\mathrm{OH})$ and blend composition. Dynamic light scattering was used mainly to monitor the formation of the complex because it is sensitive to the presence of particles in large size.

\section{EXPERIMENTAL}

\section{Materials and Characterization}

A series of copolymers PS(OH) differing in HFMS content was prepared by copolymerization as previously described. ${ }^{15,16}$ The product was precipitated in petroleum ether $\left(\mathrm{bp} 60-90^{\circ} \mathrm{C}\right)$ followed by repeated dissolution and precipitation.

Characterization data and compositions of the $\mathrm{PS}(\mathrm{OH})$ copolymers and PCL purchased from Scientific Polymer Products, Inc. are listed in Table I. The molar content of the hydroxyl in the copolymers was calculated from 
Table I. Features of PS(OH) copolymers

\begin{tabular}{lccc}
\hline \multicolumn{1}{c}{ Polymer } & OH content $/ \mathrm{mol} \%$ & $M_{w} \times 10^{-4}$ & $M_{w} / M_{n}$ \\
\hline PS(OH)-1 & 1.00 & 3.57 & 2.22 \\
PS(OH)-3 & 2.87 & 2.70 & 1.61 \\
PS(OH)-5 & 5.15 & 2.39 & 1.68 \\
PS(OH)-8 & 8.10 & 2.10 & 1.65 \\
PS(OH)-17 & 16.81 & 1.64 & 1.61 \\
PS(OH)-26 & 25.62 & - & - \\
PCL & - & 3.30 & 1.38 \\
\hline
\end{tabular}

fluorine analysis. The weight-average molecular weight $M_{w}$ and molecular weight distribution index $M_{w} / M_{n}$ were determined by size exclusion chromatography (SEC), based on calibration with polystyrene standards. For $\mathrm{PS}(\mathrm{OH})-26$, no reliable data could be obtained probably due to absorption of the high-hydroxyl polymer by the column.

\section{Viscosity Measurements}

The viscosity of blend solutions in toluene and tetrahydrofuran (THF) was measured with a Ubbelohde viscometer (at $30 \pm 0.1^{\circ} \mathrm{C}$ ). The original concentration of the individual polymer was $5.0-7.0 \times 10^{-3} \mathrm{~g} \mathrm{ml}^{-1}$. Measurement of the apparent reduced viscosity $\eta_{\mathrm{sp}} / c$ of $\mathrm{PS}(\mathrm{OH}) / \mathrm{PCL}$ blends as a function of the composition was conducted via mixing the solutions of PCL and $\mathrm{PS}(\mathrm{OH})$ at $30^{\circ} \mathrm{C}$ as desired. When hydroxyl content in $\mathrm{PS}(\mathrm{OH})$ was not higher than $5 \mathrm{~mol} \%$, the solution remained clear, but turned turbid at 8 and $17 \mathrm{~mol} \%$.

\section{Laser Light Scattering (LLS)}

A modified commercial LLS spectrometer (ALV/SP$125)$ with a multi-I digital time correclater (ALV-5000) and solid-state Laser (ADLAS DPY425 II, output power $\cong 400 \mathrm{~mW}$ at $\lambda_{\mathrm{o}}=532 \mathrm{~nm}$ ) was used. The incident beam was vertically polarized with respect to the scattering plane. The experimental conditions for determining hydrodynamic radius $R_{\mathrm{h}}$ via measuring the translational diffusion coefficient $D$ are described in previous papers. ${ }^{4,9}$

Solutions of the two component polymers were prepared by dissolving the polymers in a proper amount of solvent, i.e., toluene or $\mathrm{THF}$, followed by diluting to $1.0 \times 10^{-3} \mathrm{~g} \mathrm{~mL}^{-1}$ solutions, respectively. For blend solutions containing $\mathrm{PS}(\mathrm{OH})-26$, a low concentration of $1.0 \times 10^{-4} \mathrm{~g} \mathrm{~mL}^{-1}$ for the both components was used. Dust-free polymer solutions were made by filtration through a $0.2 \mu \mathrm{m}$ Waterman PTFE filter. Mixing of the component polymer solutions was carried out directly in a scattering cell. Following one dust-free component solution with calculated volume added to the scattering cell, the dust-free counterpart solution was added in drops with gentle agitation. All measurements were done at $25.0 \pm 0.1^{\circ} \mathrm{C}$ and scattering angle of $15^{\circ}$. In viscosity and LLS studies, the compositions of blends were expressed as unit fractions of $\mathrm{PS}(\mathrm{OH})$ including styrene and HFMS in the mixture.

\section{RESULTS AND DISCUSSION}

\section{Viscosity Behavior}

Since intermacromolecular complexation in solutions always accompanies contraction or collapse of the com-

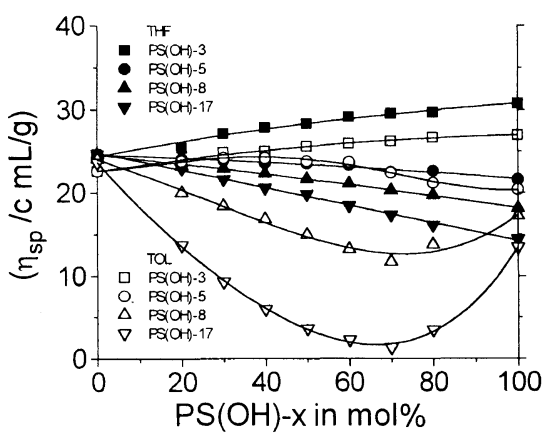

Figure 1. Reduced viscosity $\eta_{\mathrm{sp}} / c$ of solutions of PS(OH)- $x / \mathrm{PCL}$ in toluene and THF as a function of the molar unit fraction, i.e., monomer ratio of the unis of $\mathrm{PS}(\mathrm{OH})$ to those of $\mathrm{PS}(\mathrm{OH})$ plus PCL. Measuring temperature: $30 \pm 0.1^{\circ} \mathrm{C}$, original concentration of the individual polymer being $5.0 \times 10^{-3} \mathrm{~g} \mathrm{~mL}^{-1}$ except for PS(OH)-17/PCL at $7.0 \times 10^{-3} \mathrm{~g} \mathrm{~mL}^{-1}$.

ponent polymer coils, the profiles of reduced viscosity $\eta_{\mathrm{sp}} / c$ versus composition were used to monitor complexation. Previous papers report the viscosity behavior of blends of $\mathrm{PS}(\mathrm{OH}) / \mathrm{PMMA},{ }^{2} \mathrm{PS}(\mathrm{OH}) \mathrm{PBMA},{ }^{5} \mathrm{STVPh} /$ STVPy, ${ }^{3,4}$ and STVPh/PEMA. ${ }^{8-11}$ In all cases, depending on hydrogen bonding density, the solutions showed two viscosity-composition relationships, corresponding to separated coils and complex aggregates, respectively. Figure 1 shows the reduced viscosity of $\mathrm{PS}(\mathrm{OH}) / \mathrm{PCL}$ as a function of composition in toluene and THF. In toluene, a typical inert solvent with no effect on hydrogen bonding between the components, there are clearly two viscosity-composition relationships. For blends with low ( 3 and $5 \mathrm{~mol} \%$ ) hydroxyl content in $\mathrm{PS}(\mathrm{OH})$, reduced viscosity varies rather smoothly with composition and essentially obeys the additivity law of the component viscosities. Polymer coils thus exist independently. However, for blends with higher (8 and $17 \mathrm{~mol} \%$ ) hydroxyl in $\mathrm{PS}(\mathrm{OH})$, reduced viscosity showed substantial negative deviation from the additivity rule. This reflects contraction and collapse of the component polymer coils due to the formation of the complex aggregates. $^{2-6,8-11}$ In other words, transition from polymer coils to intermolecular complex takes place when hydroxyl content in $\mathrm{PS}(\mathrm{OH})$ increases from 5 to $8 \mathrm{~mol} \%$. Generally, when using viscometry to judge complexation, precipitation of polymers due to low solubility of complex often seriously disturbs measurement. This is the case for PS(OH)-26/PCL. After filtration to remove the complex precipitate, the solution showed viscosity close to zero. This means that the component polymers joined to the complex precipitate completely. However, at much lower concentrations $\left(\sim 1.0 \times 10^{-4}\right.$ $\left.\mathrm{g} \mathrm{mL}^{-1}\right)$, the polymer pair formed complex stable in toluene. A direct view of the complex is thus possible by dynamic light scattering.

Polymer pairs in THF show quite different behavior. In THF, no matter how high the hydroxyl content in $\mathrm{PS}(\mathrm{OH})$, blend viscosity follows the additivity rule. This is understandable since $\mathrm{THF}$, a proton-acceptor, competes with PCL for forming complex with protondonating polymer $\mathrm{PS}(\mathrm{OH})$. When THF serves as the solvent in viscosity measurement, the molar concentration of THF is about twice that of PCL unit. Therefore, complexation of PCL with $\mathrm{PS}(\mathrm{OH})$ is completely 


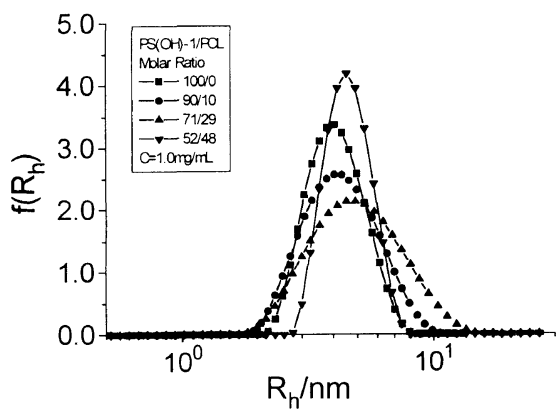

Figure 2. Hydrodynamic radius distribution $f\left(R_{\mathrm{h}}\right)$ of $\mathrm{PS}(\mathrm{OH})-1$ and $\mathrm{PS}(\mathrm{OH})-1 / \mathrm{PCL}$ blends with various compositions in toluene.

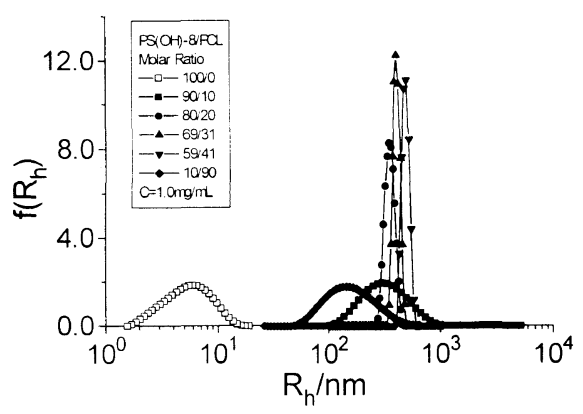

Figure 3. Hydrodynamic radius distribution $f\left(R_{\mathrm{h}}\right)$ of $\mathrm{PS}(\mathrm{OH})-8$ and $\mathrm{PS}(\mathrm{OH})-8 / \mathrm{PCL}$ blends with various compositions in toluene.

depressed.

\section{Dynamic LLS Study}

Aggregation between the unlike chains causes variation in apparent mass and hydrodynamic radius. Therefore, LLS is believed to be efficient to monitor this aggregation, especially in very dilute solution. Figures 2,3 , and 4 depict hydrodynamic radius distributions $f\left(R_{\mathrm{h}}\right)$ of $\mathrm{PS}(\mathrm{OH})-1, \mathrm{PS}(\mathrm{OH})-8, \mathrm{PS}(\mathrm{OH})-26$, and blends with PCL in toluene. Since the refractive index increase of PCL in toluene is close to zero, $\mathrm{PS}(\mathrm{OH})$ makes predominate contribution to the light scattering of blend solutions and consequently PCL could not be 'seen' in this LLS study.

As shown in Figure 2, in comparison with pure $\mathrm{PS}(\mathrm{OH})-1$, the peak value and distribution of $R_{\mathrm{h}}$ of $\mathrm{PS}(\mathrm{OH})-1$ in $\mathrm{PS}(\mathrm{OH})-1 / \mathrm{PCL}$ blend solutions varied slightly, so there was no indication of combination of unlike polymer chains.

When hydroxyl content in $\mathrm{PS}(\mathrm{OH})$ increases to $8 \mathrm{~mol} \%$, blend solutions show different behavior. In Figure 3, the peak value of $R_{\mathrm{h}}$ of pure $\mathrm{PS}(\mathrm{OH})-8$ is about $6 \mathrm{~nm}$ while that of $\mathrm{PS}(\mathrm{OH})-8$ in the blends moves to a size range larger than $100 \mathrm{~nm} . R_{\mathrm{h}}$ and its distribution strongly depend on the composition of the blends. This substantial variation as adding PCL in PS(OH) clearly indicates the formation of macromolecular aggregates due to complexation between the unlike chains. It is important to note that $R_{\mathrm{h}}$ of $\mathrm{PS}(\mathrm{OH})$ in $\mathrm{PS}(\mathrm{OH})-8 / \mathrm{PCL}$ with unit composition of about $70 / 30$ reaches the largest peak value about $600 \mathrm{~nm}$.

In Figure 4, pure $\mathrm{PS}(\mathrm{OH})-26$ in toluene exhibits a rather broad distribution $f\left(R_{\mathrm{h}}\right)$ with a tail extending to about $100 \mathrm{~nm}$ which may be attributed to self-association of $\mathrm{PS}(\mathrm{OH})-26$. Yang et al. ${ }^{17}$ reported that for the

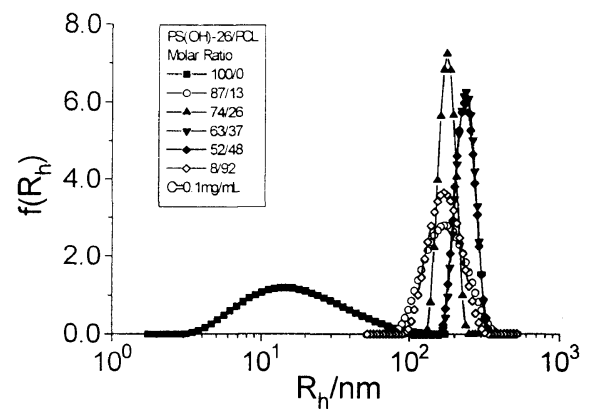

Figure 4. Hydrodynamic radius distribution $f\left(R_{\mathrm{h}}\right)$ of $\mathrm{PS}(\mathrm{OH})-26$ and $\mathrm{PS}(\mathrm{OH})-26 / \mathrm{PCL}$ blends with various compositions in toluene.

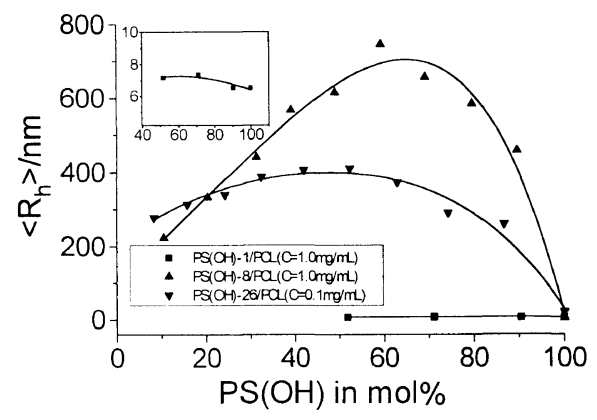

Figure 5. Average hydrodynamic radius $\left\langle R_{\mathrm{h}}\right\rangle$ of $\mathrm{PS}(\mathrm{OH}) / \mathrm{PCL}$ blends in toluene as a function of the molar unit fraction of $\mathrm{PS}(\mathrm{OH})$. The insertion is for $\mathrm{PS}(\mathrm{OH})-1 / \mathrm{PCL}$.

monomer p-(2,2,2-trifluoro-1-hydroxy-1-trifluoromethyl)ethyl styrene, the association equilibrium constants for dimer and multimer are 2.32 and 3.41, respectively. Although the association equilibrium constants are not very large, it seems reasonable that the self-association becomes detectable when hydroxyl content in $\mathrm{PS}(\mathrm{OH})$ chain is as high as $26 \mathrm{~mol} \%$, because LLS is particularly sensitive to the presence of large particles. Compared to pure PS(OH), in blend solutions of PS(OH)-26/PCL, $R_{\mathrm{h}}$ distribution of $\mathrm{PS}(\mathrm{OH})$ completely changes. When only $13 \%$ PCL is added to the PS(OH) solution, the peak position moves to $170 \mathrm{~nm}$. Further adding PCL causes the $R_{\mathrm{h}}$ peak of the complex aggregates to increase to much larger $R_{\mathrm{h}}$. For the blend with a $1: 1$ base ratio, the $R_{\mathrm{h}}$ peak reaches as high as $240 \mathrm{~nm}$. For blend solutions comprising $\mathrm{PS}(\mathrm{OH})-26$, a low concentration of $1.0 \times$ $10^{-4} \mathrm{~g} \mathrm{~mL}^{-1}$, one order of magnitude less than that for the cases with $\mathrm{PS}(\mathrm{OH})-1$ and 8 , was used to avoid precipitation of the complex.

The results in both Figures 3 and 4 show that particle size distribution noticeably depends on blend composition. In some cases, very narrow distribution is obtained. We do not know the reasons for this yet.

Figure 5 shows the blend composition dependence of the average hydrodynamic radius $\left\langle R_{\mathrm{h}}\right\rangle$ for $\mathrm{PS}(\mathrm{OH}) / \mathrm{PCL}$ blends. For PS(OH)-1/PCL, $\left\langle R_{\mathrm{h}}\right\rangle$ of $\mathrm{PS}(\mathrm{OH})$ in blends shows little variation, reflecting the independence of unlike polymer coils (see the insert). However, for $\mathrm{PS}(\mathrm{OH})-8 / \mathrm{PCL}$ and PS(OH)-26/PCL, $\left\langle R_{\mathrm{h}}\right\rangle$ varies with blend composition substantially, showing much larger $\left\langle R_{\mathrm{h}}\right\rangle$ than average values calculated from the components. For PS(OH)-8/PCL, the curve gives a maximum at a composition of $\mathrm{PS}(\mathrm{OH}) / \mathrm{PCL}$ around $70 / 30$, the same as that for minimum viscosity shown in Figure $1 . R_{\mathrm{h}}$ of 


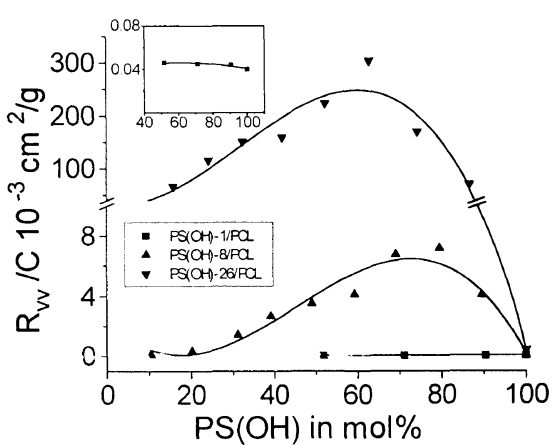

Figure 6. Excess Rayleigh ratios $R_{\mathrm{vv}} / \mathrm{C}$ for toluene solution of $\mathrm{PS}(\mathrm{OH})-x / \mathrm{PCL}$ blends as a function of the molar unit fraction of $\mathrm{PS}(\mathrm{OH})$. The insertion is for PS(OH)-1/PCL.

$\mathrm{PS}(\mathrm{OH})-8 / \mathrm{PCL}$ is apparently larger than that of $\mathrm{PS}(\mathrm{OH})-$ 26/PCL for most compositions although the density of hydrogen bonding of the former is much less than the latter. This is understandable if the concentration used of the former is one order magnitude larger than the latter is taken into account.

\section{Static LLS Study}

For dilute polymer solution, excess absolute scattered intensity, i.e., excess Rayleigh ratio $\left[R_{\mathrm{vv}}(\theta)\right]$, can be expressed as a function of concentration $C$ and scattering angle $\theta$ :

$$
\frac{K C}{R_{\mathrm{vv}}(\theta)} \cong \frac{1}{M_{w}}\left(1+\frac{\left\langle R_{\mathrm{g}}^{2}\right\rangle q^{2}}{3}\right)+2 A_{2} C
$$

where $M_{w}$ is weight-average molecular weight, $A_{2}$, second Virial coefficient, and $K=4 \pi^{2} n^{2}(\partial n / \partial C)^{2} /\left(N_{\mathrm{A}} \lambda_{0}{ }^{4}\right)$ with $N_{\mathrm{A}}, n$ and $\lambda_{0}$, Avogadro's number, solvent refractive index, and wavelength of light in vacuo, respectively, and $q=\left(4 \pi n / \lambda_{0}\right) \sin (\theta / 2)$. For scattering angles approaching zero, $R_{\mathrm{vv}}$ depends on $M_{w}$ and $A_{2}$ of the polymer particles. In polymer solution, the higher the weightaverage molecular mass and more unfavorable the polymer-solvent interaction, the larger is $R_{\mathrm{vv}}$. If we consider polymer complex due to hydrogen bonding to be a physically connected species, the higher the mass of the aggregates formed and the stronger the interaction between complex polymers, the larger should be $R_{\mathrm{vv}}$.

Figure 6 shows plots of reduced excess Rayleigh ratios $R_{\mathrm{vv}} / C$ versus composition for $\mathrm{PS}(\mathrm{OH}) / \mathrm{PCL}$ blends in toluene. $R_{\mathrm{vv}} / C$ of $\mathrm{PS}(\mathrm{OH})-1$ is also almost the same over the composition studied (see the insert). The apparent $M_{w}$ thus does not vary substantially, in other words, both macromolecules exist in single chains. But for $\mathrm{PS}(\mathrm{OH})-8 / \mathrm{PCL}, \mathrm{PS}(\mathrm{OH})-26 / \mathrm{PCL}$ blends, $R_{\mathrm{vv}}$ is always larger than the values of additivity and reaches maximum when blend composition is $80 / 20$ and $65 / 35 \mathrm{~mol} / \mathrm{mol}$ respectively. Although the concentration used for $\mathrm{PS}(\mathrm{OH})-8 / \mathrm{PCL}$ is much higher than that for $\mathrm{PS}(\mathrm{OH})$ 26/PCL, $R_{\mathrm{vv}}$ of the former over the whole composition range is only about $1 / 50-1 / 100$ the latter. This means that, due to higher hydrogen bonding density, $\mathrm{PS}(\mathrm{OH})-26$ forms complex aggregates with PCL having much larger mass than $\mathrm{PS}(\mathrm{OH})-8$. Recalling that $R_{\mathrm{h}}$ of $\mathrm{PS}(\mathrm{OH})-8$ in blends is apparently larger than that in $\mathrm{PS}(\mathrm{OH})-26 / \mathrm{PCL}$, obviously, $\mathrm{PS}(\mathrm{OH})-26$, even at a lower concentration, due to its higher density of interaction sites, should form aggregates with much higher mass density. The complex aggregate particles of $\mathrm{PS}(\mathrm{OH})-26 / \mathrm{PCL}$ are thus much more compact than those of PS(OH)-8/PCL.

Acknowledgments. This work was supported by the National Natural Science Foundation of China and also by the National Key Projects for Fundamental Research "Macromolecular Condensed State," the State Science and Technology Commission of China.

\section{REFERENCES}

1. M. Jiang, W. Chen, and T. Yu, Polymer, 32, 984 (1991).

2. X. Qiu and M. Jiang, Polymer, 35, 5084 (1994).

3. M. Xiang, M. Jiang, Y. Zhang, C. Wu, and L. Feng, Macromolecules, 30, 2313 (1997).

4. Y. Zhang, M. Xiang, M. Jiang, and C. Wu, Macromolecules, 30, 6084 (1997).

5. X. Qiu and M. Jiang, Polymer, 36, 3601 (1995).

6. M. Jiang, X. Qiu, W. Qin, and L. Fei, Macromolecules, 28, 730 (1995).

7. X. Qiu and M. Jiang, Chemical Journal of Chinese Universities (in Chinese), 14, 1625 (1993).

8. M. Xiang, M. Jiang, Y. Zhang, and C. Wu, Macromolecules, 30, 5339 (1997).

9. Y. Zhang, M. Xiang, M. Jiang, and C. Wu, Macromolecules, 30, 2035 (1997)

10. L. Zhu, M. Jiang, L. Liu, H. Zhou, L. Fan, Y. Zhang, Y. B. Zhang, and C. Wu, J. Macromol. Sci.-Phys., B37, 805 (1998).

11. L. Zhu, M. Jiang, L. Liu, H. Zhou, L. Fan, and Y. Zhang, J. Macromol. Sci.-Phys., B37, 827 (1998).

12. H. Zhou, M. Xiang, W. Chen, and M. Jiang, Macromol. Chem. Phys., 198, 809 (1997).

13. R. de Juana and M. Cortazar, Macromolecules, 26, 1170 (1993).

14. M. J. Fernandez-Berridi, M. Valero, A. Martinez de Iiarduya, E. Espi, and J. J. Iruin, Polymer, 34, 38 (1993).

15. X. Cao, M. Jiang, and T. Yu, Makromol. Chem., 190, 117 (1989).

16. E. Pearce, T. K. Kwei, and B. Min, J. Macromol. Sci. Chem., A21, 1181 (1984).

17. X. Yang, P. C. Painter, M. M. Coleman, E. M. Pearce, and T. K. Kwei, Macromolecules, 25, 2156 (1992). 